\title{
Efektifitas Kinerja Bangunan Pengaman Pantai di Desa Munte Kabupaten Luwu Utara
}

\author{
Muh. Akhsan Samaila ${ }^{1}$, Siti Marohatus Hidayatun ${ }^{2}$ \\ 1,2 Program Studi Teknik Sipil Universitas Muhammadiyah Sorong
}

\begin{abstract}
Abstrak
Garis Pantai Munte yang berhadapan dengan Teluk Bone, lebih banyak menghadapi masalah abrasi pantai yang menyebabkan permukiman dan fasilitas umum seperti sekolah, masjid terancam oleh hempasan gelombang. Dalam menangani permasalahan tersebut dilakukan pendekatan hard approach dengan pembangunan struktur bangunan pantai. Kinerja bangunan pantai diukur dengan efektifitas fungsionalnya untuk mereduksi energi gelombang. Untuk mencapai kriteria efektif maka dilakukan identifikasi masalah serta konsep kajian dengan mengumpulkan data primer dan sekunder. Kondisi bangunan eksisting pada Pantai Munte berupa groin dan detached breakwater. Dari hasil analisis deformasi gelombang menggunakan pemodelan terhadap bangunan eksisting, tinggi gelombang yang sampai dibibir pantai rata - rata sebesar $0.86 \mathrm{~m}$ sedangkan kombinasi groin dan detached breakwater mereduksi tinggi gelombang yang sampai ke pantai hingga $0.26 \mathrm{~m}$. Hasil tersebut menunjukkan efektifitas bangunan pengaman pantai sebesar $30.23 \%$. Hasil perhitungan deformasi gelombang menggunakan pemodelan numerik menunjukkan hasil yang mendekati dengan perhitungan secara analitik sehingga pemodelan dapat digunakan untuk memperoleh salah satu parameter efektifitas yaitu reduksi tinggi gelombang.
\end{abstract}

Kata kunci : pantai munte, deformasi gelombang, hard approach, reduksi energi gelombang

\section{Pendahuluan}

Metode yang digunakan untuk melindungi pantai secara garis besar dibagi 2 cara pendekatan yaitu pendekatan keras (hard approach) dan pendekatan lunak (soft approach). Hard approach meliputi pembangunan struktur sipil seperti breakwater, seawall, revetment, groin, jetty, dll, sedangkan soft approach meliputi perlindungan dengan vegetasi dan pengisian pasir (beach nourisment).

Pendekatan hard approach dengan membangun struktur sipil pengaman pantai terkadang gagal dalam memenuhi fungsinya. Kegagalan atau tidak terpenuhinya fungsi tersebut dapat disebabkan oleh kekeliruan dalam pertimbangan teknis perencanaan atau kesalahan konstruksi. Terdapat kesan bahwa sering terjadi kekeliruan dalam memilih tipe dan/atau material konstruksi pengaman pantai dari yang semestinya, keliru dalam memprediksikan unjuk kerja struktur bila telah beroperasi nantinya. Keliru dalam penerapan teori keteknikpantaian akan berdampak pada kegagalan sistem pengamanan pantai memenuhi fungsinya.

Kinerja bangunan pantai diukur dengan efektifitas fungsionalnya, kemampuannya melawan energi gelombang, arus dan tekanan hidrolika lainnya tanpa mengalami kerusakan dan keruntuhan serta ketahanan terhadap cuaca dan waktu. Kinerja bangunan tersebut akan sangat ditentukan oleh kebenaran data perencanaan, pemahaman terhadap kondisi yang terjadi, penetapan kriteria yang benar untuk mendukung fungsi tujuan dan pendekatan/metodologi disain yang digunakan. Tercapainya fungsi bangunan yang diinginkan diharapkan mampu menyelesaikan permasalahan yang akan maupun sedang terjadi di lokasi studi.

Dilihat dari segi topografi, Pantai Munte Kabupaten Luwu Utara terletak pada pesisir pantai yang daratannya relatif datar, dimana menjadi tempat pemukiman dan lahan tambak disekitarnya. Garis Pantai Munte yang berhadapan dengan Teluk Bone, lebih banyak menghadapi masalah abrasi pantai menyebabkan permukiman dan fasilitas umum seperti sekolah, masjid terancam oleh hempasan gelombang. Permasalahan abrasi di Pantai Munte telah berlangsung lama dan telah mengakibatkan beberapa bagian prasarana umum seperti jalan telah hilang oleh abrasi gelombang dan rusaknya bangunan pengaman pantai. Pada kondisi pasang air laut yang tinggi disertai dengan hempasan gelombang, rumah-rumah penduduk, masjid dan sekolah kerap mendapatkan genangan air dan bahkan beberapa rumah yang sudah tergerus dengan gelombang.

Permasalahan erosi/abrasi dan akresi pantai adalah mekanisme alamiah yang selalu terjadi pada garis pantai selama energi gelombang dan arus menerpa pantai. Hal yang perlu dilakukan adalah memelihara lingkungan pantai agar garis pantai berada pada kondisi stabil dinamis yaitu meskipun selalu terjadi erosi dan akresi tetapi dalam satu periode musim secara rata-rata garis pantai tetap pada posisi semula. Permasalahan ini memerlukan penanganan yang tepat dengan mempertimbangkan 
banyak faktor dalam jangka panjang dan merupakan bagian dari suatu strategis perencanaan yang berpedoman pada kebijakan Integrated Coastal Zone Management (ICZM).

\section{Metode Penelitian}

\subsection{Lokasi Penelitian}

Lokasi yang ditinjau merupakan segmen Pantai Munte dengan beberapa sungai yang bermuara di sekitar Pantai Munte yaitu Muara Rampoang di sebelah barat yang merupakan muara gabungan Sungai Bone-Bone, Patila, Rampoang dan Minna serta muara Sungai Bungadidi di sebelah timur.

Cakupan studi meliputi daerah pantai di sebelah selatan dan utara. Penggunaan lahan di darat meliputi pemukiman, persawahan, dan tambak (Gambar 1). Sedangkan daerah pantai ke arah laut dimanfaatkan sebagai kawasan perikanan tangkap dan budidaya rumput laut. Penggunaan lahan di darat yang berhubungan langsung dengan bibir pantai adalah pemukiman dan pertambakan. Bangunan pantai yang terdapat pada daerah studi yaitu revetment, groin tipe $\mathrm{T}$ dan detached breakwater.

\subsection{Pengumpulan Data}

Untuk mencapai hasil kajian kinerja bangunan yang diharapkan dari aspek pendekatan dan metode, dilakukan beberapa pengumpulan data baik primer maupun sekunder. Untuk data primer dilakukan survey bathimetri dan kecepatan arus sedangkan untuk data sekunder diperoleh data topografi, data pasang surut dan data angin.

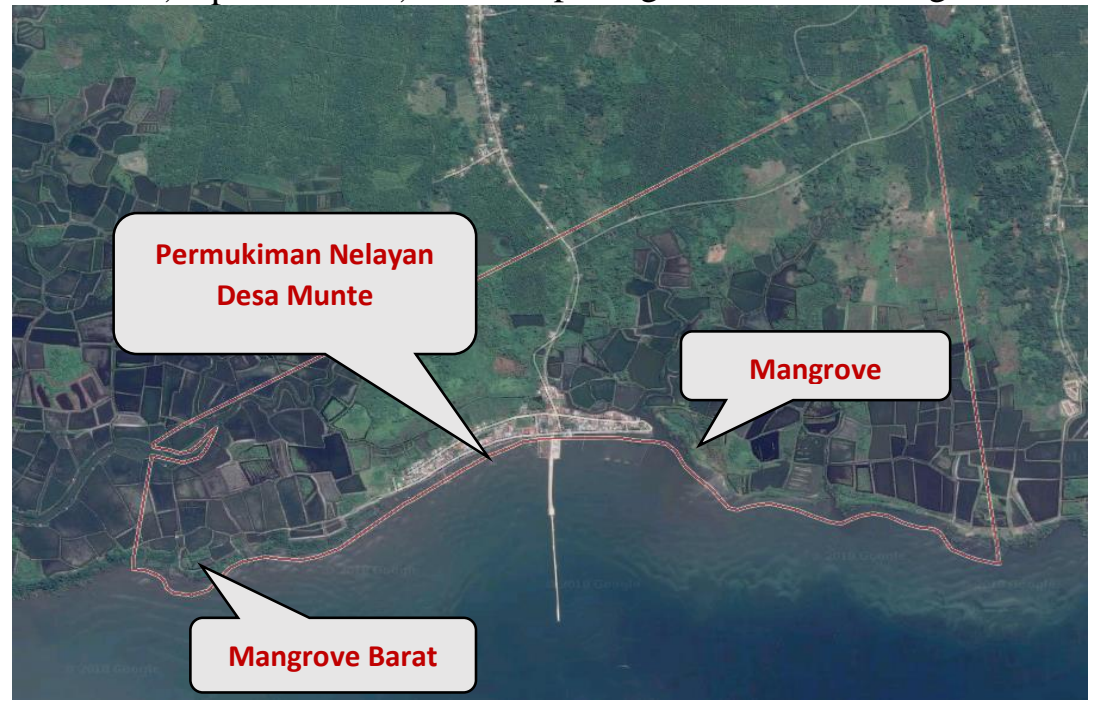

Gambar 1. Kondisi Pantai Munte Kabupaten Luwu Utara

Proses identifikasi masalah hingga analisis data dirangkum dalam bagan alir seperti yang disajikan pada Gambar 2.

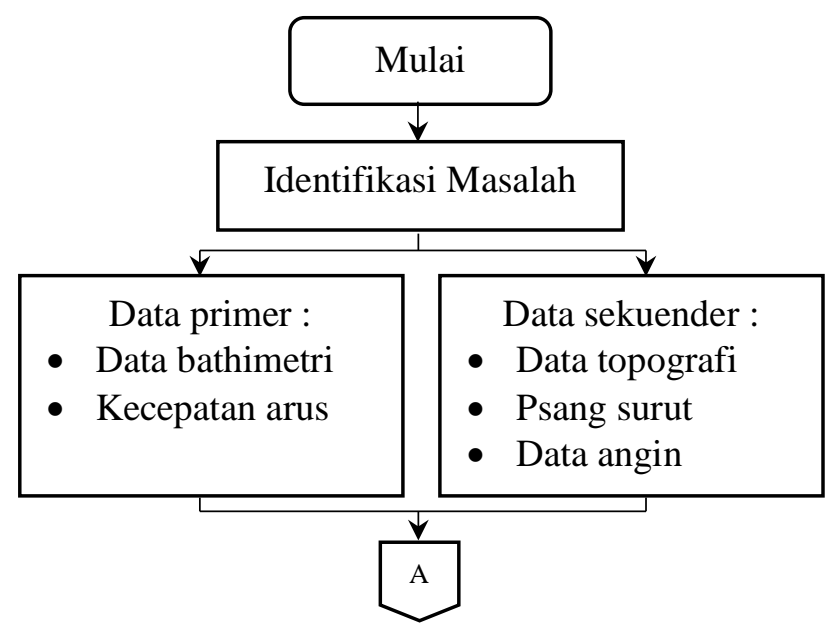

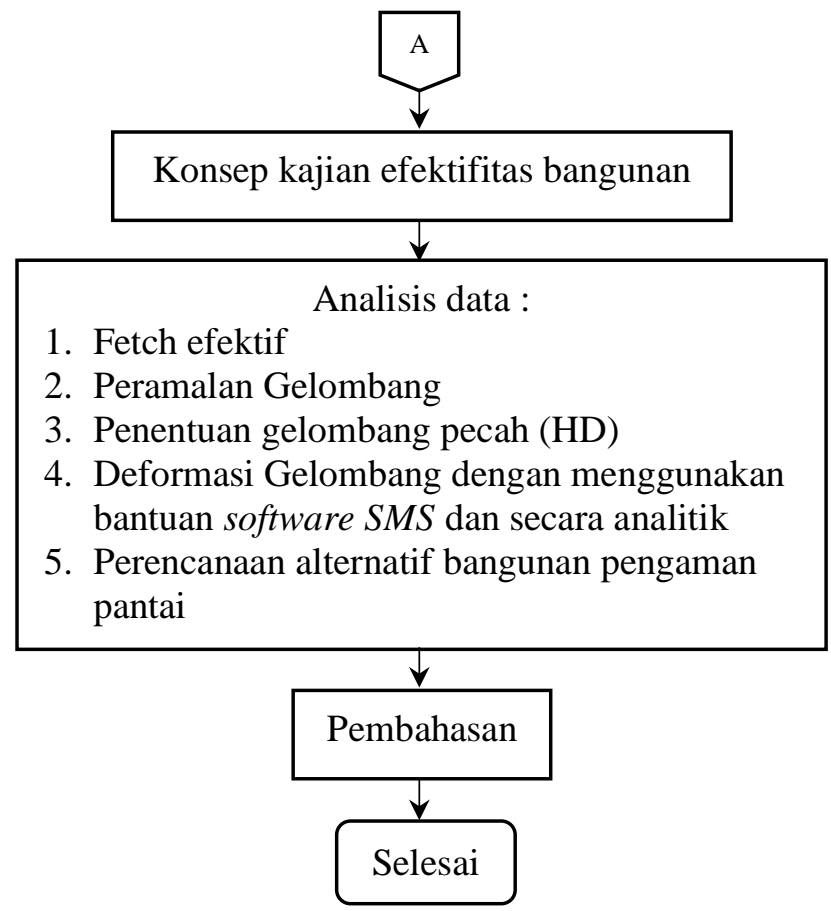

Gambar 2. Bagan alir penelitian 


\section{Hasil dan Pembahasan}

\subsection{Fetch Efektif}

Gelombang yang berpengaruh di Pantai Munte adalah gelombang yang dibangkitkan oleh angin lokal dari arah selatan, tenggara, barat daya dan timur. Arah gelombang laut dalam yang berpengaruh di Pantai Munte dan daerah pembangkitannya ditunjukkan dalam Peta Gambar 3.

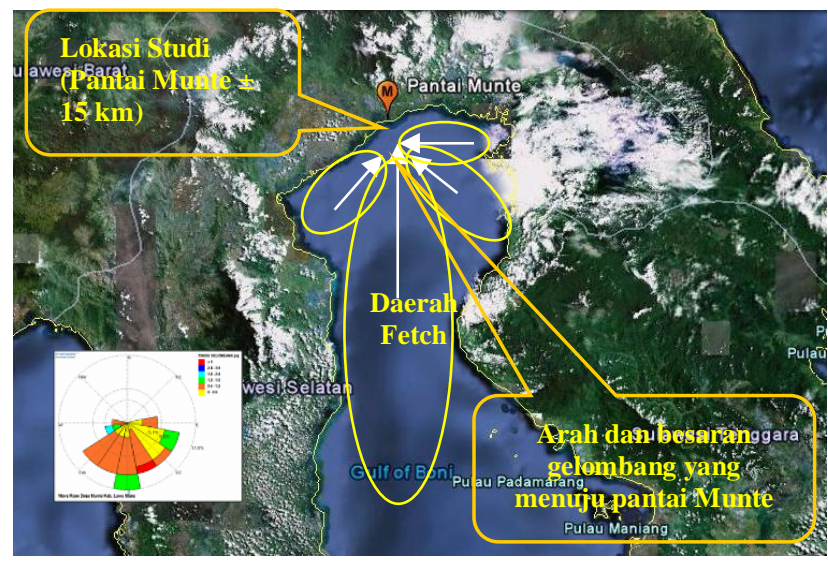

Gambar 3. Gelombang dan daerah pembangkitannya di Pantai Munte

Daerah pembangkitan gelombang (fetch efektif) dari beberapa arah pembangkitan gelombang diperlihatkan pada Tabel 1 .

Tabel 1. Fetch efektif lokasi penelitian Arah Utama Panjang Fetch (km)

\begin{tabular}{cl}
\hline Selatan & 521,01 \\
Tenggara & 178,37 \\
Barat Daya & 246,67 \\
\hline
\end{tabular}

\subsection{Hindcasting Gelombang}

Peramalan gelombang

(hindcasting) menggunakan metode SPM Volume I 1984. Model hindcast gelombang yang disederhanakan tersebut banyak digunakan untuk memperkirakan iklim gelombang di lokasi di mana tidak ada data gelombang yang tersedia (Hurdle dan Stive, 1989). Melalui penyederhanaan tersebut terdapat kekurangan diantaranya inkonsistensi formula pembangkitan gelombang oleh angin yang konstan.

Proses hindcasting berdasarkan data meteorologi lampau dalam hal ini adalah data angin. Data diperoleh dari Stasiun Masamba (Luwu Utara) selama 11 tahun dari tahun 2000 sampai tahun 2010 sebagai stasiun terdekat dan diasumsi dapat mewakili kejadian angin di Pantai Munte. Distribusi kejadian angin dari data yang diperoleh merupakan hasil pengelompokan data angin bulanan yang dapat dilihat pada Gambar 4.

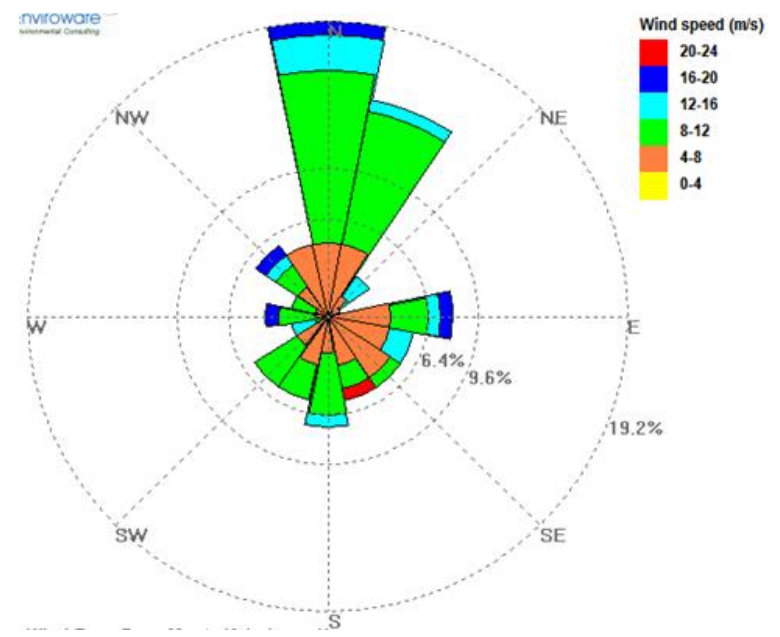

Gambar 4. Windrose distribusi kecepatan dan arah angin bulanan

Berdasarkan hasil pengolahan data angin dari Stasiun Masamba (Luwu Utara) tahun 2000 - 2010, dapat diketahui bahwa angin dominan terjadi dari arah utara pantai munte dengan jumlah kejadian sebanyak 33,6\% dengan kecepatan 4 sampai dengan 20 knot.

Data angin yang diperoleh kemudian diolah menggunakan metode SPM yang telah disebutkan sebelumnya untuk mendapatkan distribusi gelombang seperti yang disajikan pada Gambar 5.

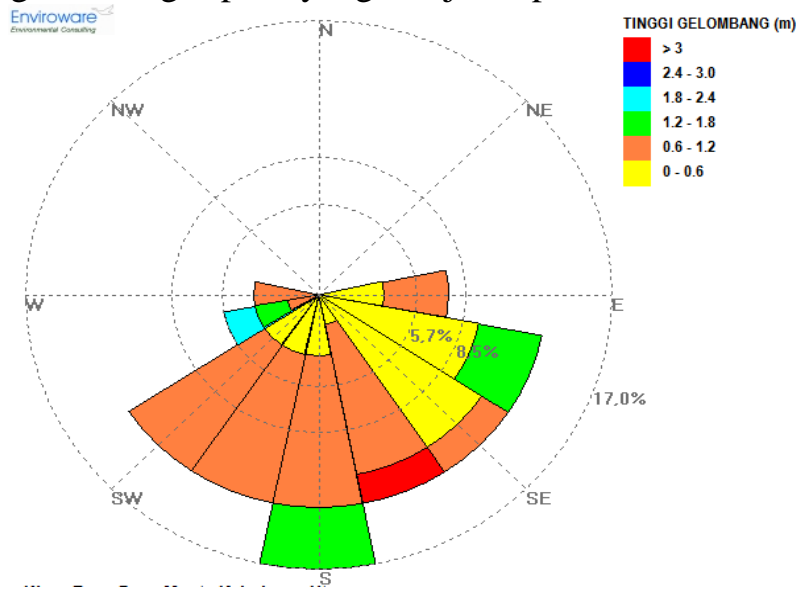

Gambar 5. Wave Rose dan distribusi Arah gelombang Pantai Munte

Sedangkan kejadian gelombang berdasarkan interval tinggi gelombang dapat dilihat pada Tabel 2.

Tabel 2. Persentase kejadian berdasarkan interval tinggi gelombang

\begin{tabular}{ccc}
\hline Interval (m) & Jumlah Data & Persentase \\
\hline $0-0,6$ & 20 & 37,74 \\
\hline $0,6-1,2$ & 26 & 49,06 \\
\hline $1,2-1,8$ & 5 & 9,43 \\
\hline $1,8-2,4$ & 1 & 1,89 \\
\hline $2,4-3,0$ & 0 & 0,00 \\
\hline$>3,0$ & 1 & 1,89 \\
\hline
\end{tabular}




\subsection{Gelombang Representatif}

Data gelombang yang diperoleh dari peramalan melalui data angin harus dipilih suatu tinggi yang dapat mewakili dan disebut tinggi gelombang representatif. Oleh karena itu data gelombang yang ada dipilih salah satu tinggi gelombang yang paling besar nilai setiap tahunya, kemudian dihitung tinggi gelombang yang dapat mewakili dengan suatu tingakat keyakinan tertentu. Dalam studi ini untuk menentukan suatu tinggi gelombang yang representatif dengan kala ulang tertentu digunakan metode Fisher-Tippet tipe I (CEM, Hal II-8-7)

Tinggi dan periode gelombang yang diperoleh adalah tinggi dan periode gelombang signifikan. Sehingga tinggi dan periode gelombang laut dalam representatif yang diperoleh juga berupa parameter gelombang signifikan. Pada Tabel 3 diperoleh tinggi dan periode gelombang signifikan representatif di laut dalam dengan kala ulang 25 tahun.

Tabel 3. Tinggi dan periode gelombang laut dalam signifikan dengan kala ulang 25 tahunan

\begin{tabular}{ccc}
\hline Arah & Tinggi & Periode \\
\hline Selatan & 1,8507 & 6,710 \\
\hline Tenggara & 2.708 & 7,601 \\
\hline Barat Daya & 2.176 & 7.217 \\
\hline
\end{tabular}

\subsection{Gelombang Pecah}

Perhitungan tinggi gelombang rencana diperhitungkan adanya proses refraksi dan shoaling, dalam perambatan gelombang dari laut dalam ke pantai. Gelombang rencana pada masing-masing lokasi berbeda-beda sebab sangat dipengaruhi oleh letak bangunan dari garis pantai atau kedalaman air di depan kaki bangunan. Dalam penentuan gelombang rencana dilakukan perhitungan gelombang pecah berdasarkan kedalaman air $d$ dan tinggi gelombang datang. Berdasarkan pada grafik teori gelombang yang dirujuk dari LeMehaute (1969), tinggi gelombang pecah didekati dengan persamaan :

$$
H b=0,78 d
$$

Dari hasil perhitungan tinggi gelombang pecah selanjutnya dibuatkan grafik $H b$ dengan $d$. Disamping itu juga tinggi gelombang yang dipengaruhi dengan refraksi dan shoaling $H(K r, K s)$ dihitung dengan $H(k s, K r)=K s . K r H o$ dan dibuatkan grafik hubungan antara tinggi gelombang tersebut dengan kedalaman pada grafik yang sama dengan grafik hubungan antara kedalaman dengan tinggi gelombang pecah. Koefisien $K_{r}$ dan $K_{s}$ ditunjukkan pada Tabel 5.
Tabel 5. Koefisien refraksi dan shoaling

\begin{tabular}{|c|c|c|c|c|c|c|c|c|c|}
\hline \multirow{2}{*}{$\begin{array}{l}\text { Kedalama } \\
\quad \mathbf{n}(\mathbf{d})\end{array}$} & \multicolumn{3}{|c|}{ Selatan } & \multicolumn{3}{|c|}{ Tenggara } & \multicolumn{3}{|c|}{ Barat Daya } \\
\hline & Ks & $\mathrm{Kr}$ & $\mathbf{K s . K r}$ & Ks & $\mathbf{K r}$ & Ks.Kr & Ks & $\mathbf{K r}$ & Ks.Kr \\
\hline 0.50 & 5 & 90 & 9 & 651 & 96 & 6 & $\mathrm{Ks}$ & 52 & .568 \\
\hline 1.00 & 323 & 796 & 052 & .401 & 997 & .396 & 1.610 & 356 & .487 \\
\hline 2.00 & 138 & 0.807 & 0.918 & 1.199 & 0.997 & 1.195 & 1.367 & 63 & 0.426 \\
\hline 30 & 052 & 18 & 60 & .103 & & 99 & 1.173 & 70 & .400 \\
\hline 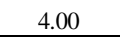 & 1.001 & 829 & 830 & 1.044 & 997 & 1.042 & 1.081 & 0.378 & .388 \\
\hline 5.0 & 0.969 & 0.840 & 0.814 & 1.006 & 0.997 & 1.003 & 1.026 & 0.386 & 0.382 \\
\hline 600 & 0.948 & 0.851 & 0.806 & 0.978 & 0.998 & 0.976 & 0.990 & 0.395 & 0.381 \\
\hline 700 & 0.933 & 0.862 & 0.804 & 0.958 & 0.998 & 0.956 & 0.964 & .404 & 0.382 \\
\hline & 23 & 0 & & 0.944 & 8 & 12 & 0.947 & 13 & .386 \\
\hline 9.00 & 0.917 & 0.882 & 0.810 & 0.933 & 0.998 & .931 & 0.934 & 0.423 & 0.391 \\
\hline 1000 & 0.914 & 0.892 & 0.816 & 0.925 & 0.998 & .924 & 0.925 & 0.433 & 0.398 \\
\hline 11.00 & 0.913 & 0.902 & 0.824 & 0.920 & 0.998 & 0.918 & 0.919 & 0.444 & 0.406 \\
\hline 12.00 & 0.913 & 0.911 & 0.833 & 0.916 & 0.999 & 0.915 & 0.916 & 0.455 & 0.416 \\
\hline 13.00 & 0.915 & 0.920 & 0.842 & 0.914 & 0.999 & 0.913 & 0.914 & 0.467 & 0.426 \\
\hline
\end{tabular}

Dengan menggunakan nilai koefisien shoaling dan koefisien refraksi, serta tinggi dan periode gelombang laut dalam seperti pada Tabel 5, dapat diperoleh grafik hubungan antara tinggi gelombang $\mathrm{H}$ $=0,78$. d dengan kedalaman d serta hubungan antara tinggi gelombang datang $\mathrm{H}(\mathrm{Ks}, \mathrm{Kr})$ dengan kedalaman untuk berbagai arah gelombang datang.

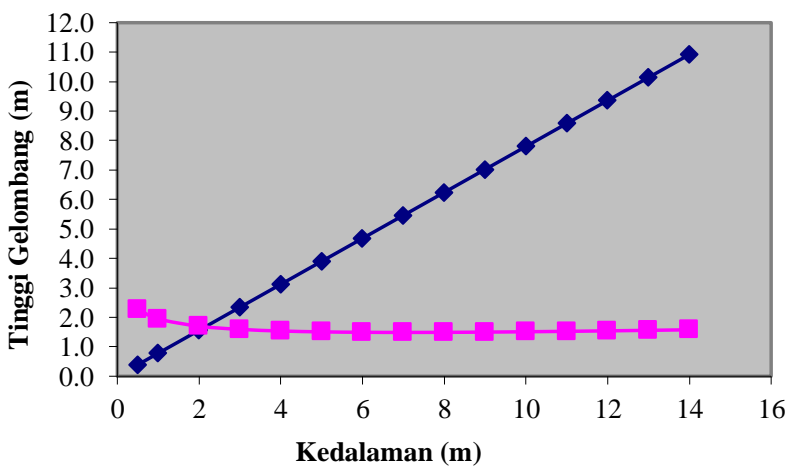

Gambar 6. Grafik hubungan antara kedalaman dengan $\mathrm{H}$ serta $\mathrm{H}(\mathrm{Ks}, \mathrm{Kr})$ dan $\mathrm{Hb}$ untuk gelombang datang dari arah selatan

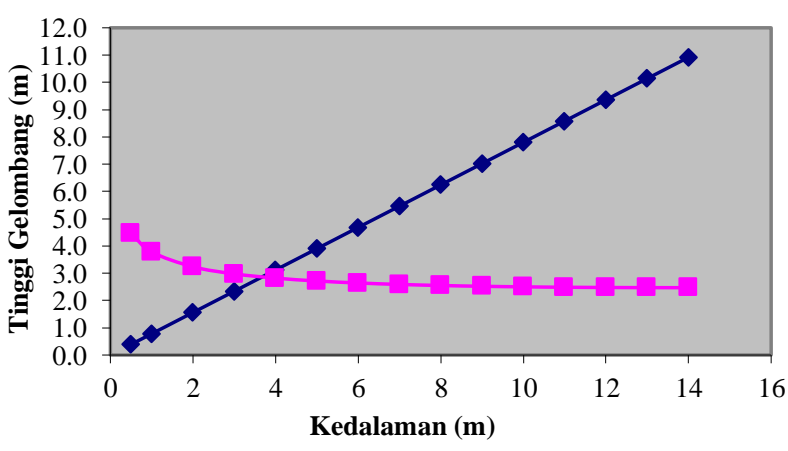

Gambar 7. Grafik hubungan antara kedalaman dengan $\mathrm{H}$ serta $\mathrm{H}(\mathrm{Ks}, \mathrm{Kr})$ dan $\mathrm{Hb}$ untuk gelombang datang dari arah tenggara 


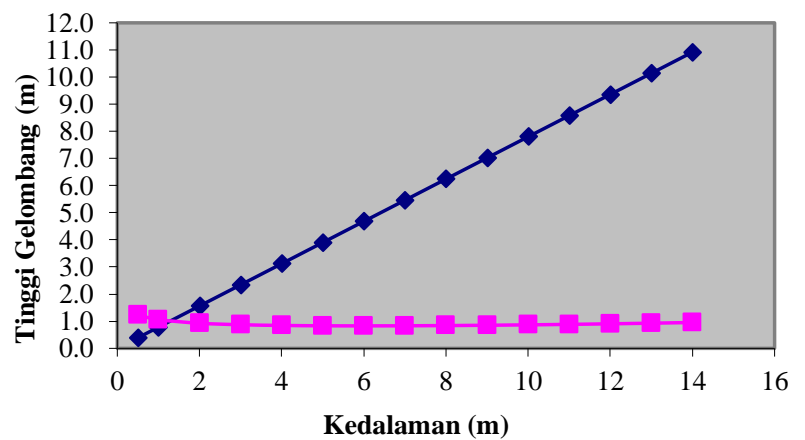

Gambar 8. Grafik hubungan antara kedalaman dengan $\mathrm{H}$ serta $\mathrm{H}(\mathrm{Ks}, \mathrm{Kr})$ dan $\mathrm{Hb}$ untuk gelombang datang dari arah barat daya

\subsection{Deformasi Gelombang (Software SMS)}

Perubahan gelombang akibat karena perubahan kedalaman maupun rintangan berupa pemecah gelombang akan ditinjau dari arah datang gelombang yang memiliki tinggi dan periode terbesar yaitu dari arah tenggara.

Pada Gambar 9 ditunjukkan berupa kontur tinggi gelombang dengan hasil perhitungan tinggi gelombang harian untuk arah gelombang dominan yaitu dari arah tenggara.

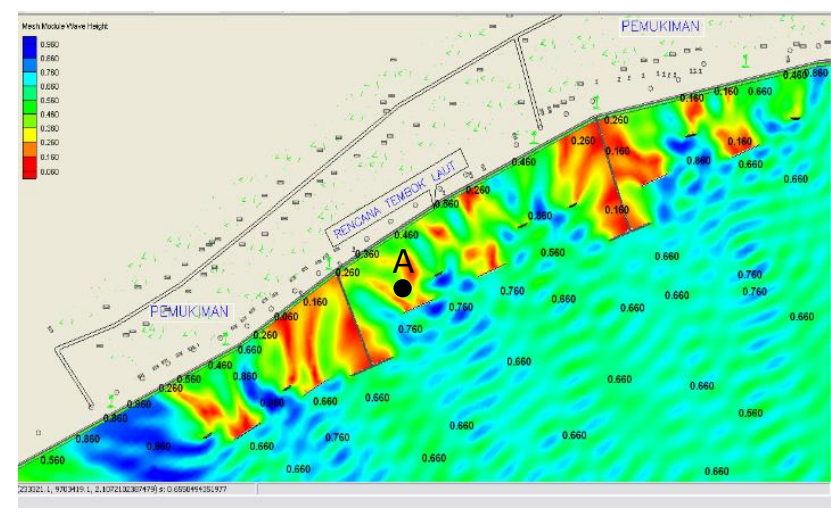

Gambar 9. Sebaran tinggi gelombang dari arah tenggara.

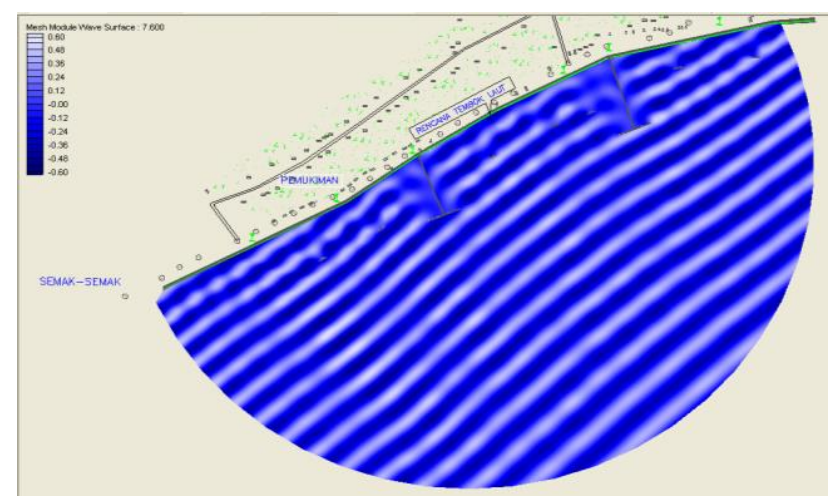

Gambar 10. Hasil rambatan gelombang dari arah tenggara

Dari Gambar 9 dapat dilihat bahwa tinggi gelombang (dengan gelombang datang dari arah tenggara) secara umum berkisar 0,06 m hingga 0,96 $\mathrm{m}$. Pada kedalaman transisi, tinggi gelombang berkisar 0,36 m sampai dengan 0,76 m. Gelombang yang sampai di bibir Pantai Munte telah mengalami transformasi sehingga tingginya menurun ke kisaran $0,06 \mathrm{~m}$ sampai dengan $0,26 \mathrm{~m}$.

\subsection{Deformasi Gelombang (Analitis)}

Pada rintangan (pemecah gelombang) tunggal, tinggi gelombang di suatu tempat di daerah terlindung tergantung pada jarak titik tersebut terhadap ujung rintangan $r$, sudut antara rintangan dan garis yang menghubungkan titik tersebut dengan ujung rintangan $\beta$, dan sudut antara arah penjalaran gelombang dan rintangan $\theta$. Perbandingan antara tinggi gelombang di titik yang terletak di daerah terlindung dan tinggi gelombang datang disebut koefisien difraksi $K^{\prime}$.

$$
\begin{aligned}
& \mathrm{H}_{\mathrm{A}}=K^{`} \mathrm{H}_{\mathrm{P}} \\
& K^{`}=\mathrm{f}(\theta, \beta, \mathrm{r} / \mathrm{L})
\end{aligned}
$$

Dengan A adalah titik yang ditinjau di belakang rintangan dan $P$ adalah ujung pemecah gelombang.

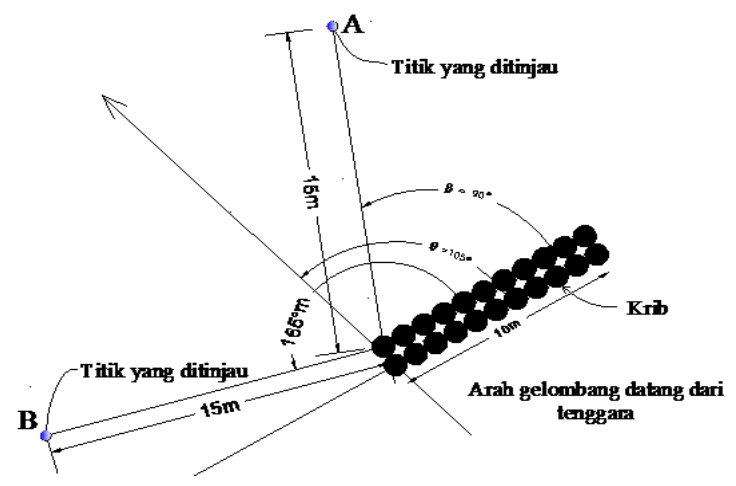

Gambar 11. Sketsa defenisi perhitungan tinggi gelombang dibelakang detached breakwater

Analisa difraksi satu titik tinjauan untuk pemecah gelombang yang telah ada (eksisting) dengan arah datang gelombang tenggara dengan data - data ramalan gelombang memberikan hasil sebagai berikut:

- Periode gelombang $(\mathrm{T})=6.71$ detik

- Sudut datang gelombang $(\theta)=105^{\circ}$

- Kedalaman air dibelakang pemecah gelombang $(\mathrm{d})=1.433 \mathrm{~m}$

- Jarak titik tinjauan $(\mathrm{r})=15 \mathrm{~m}$

- Sudut titik tinjauan $(\beta)=90^{\circ}$

- Tinggi gelombang di ujung rintangan $\left(\mathrm{H}_{\mathrm{p}}\right)=$ $0.68 \mathrm{~m}$ 
Panjang gelombang dihitung menggunakan persamaan :

$$
L_{0}=1.56 T^{2}
$$

Sehingga diperoleh $L_{0}=70.24 \mathrm{~m}$.

$$
\frac{d}{L_{0}}=\frac{1.433}{70.24}=0.0204
$$

Dari hasil $\mathrm{d} / \mathrm{L}_{0}$ akan dicari nilai panjang gelombang dari rasio $\mathrm{d} / \mathrm{L}$ dengan menggunakan lampiran C-1 pada SPM 1984. Diperoleh nilai :

$$
\frac{d}{L}=0.05915 \rightarrow L=\frac{1.433}{0.05915}=24.22
$$

Dengan menggunakan lampiran C-2 diperoleh koefisien $K^{\prime}=0.404$. Maka tinggi gelombang yang ditinjau untuk arah tenggara dengan sudut datang $(\theta)$ $=75^{\circ}$.

$H_{A}=K^{\prime} . H_{p}$

$H_{A}=(0.404) .(0.68)=0.275$

Perhitungan tinggi gelombang untuk setiap sudut tinjauan diberikan pada Tabel 6 .

Tabel 6. Rekap perhitungan tinggi gelombang untuk masing-masing sudut tinjauan

\begin{tabular}{ccccccccccccc}
\hline $\mathbf{T}$ & $\mathbf{L}_{\mathbf{0}}$ & $\mathbf{\theta}$ & $\mathbf{d}$ & $\mathbf{r}$ & $\boldsymbol{\beta}$ & $\mathbf{H}_{\mathbf{P}}$ & $\mathbf{L}$ & $\mathbf{d} / \mathbf{L}_{\mathbf{0}}$ & $\mathbf{d} / \mathbf{L}$ & $\mathbf{r} / \mathbf{L}$ & $\mathbf{K}^{\prime}$ & $\mathbf{H}_{\mathbf{A}}$ \\
\hline 6.71 & 70.236 & 105 & 1.433 & 15 & 15 & 0.68 & 24.86 & 0.0204 & 0.0576 & 0.6034 & 0.274 & 0.1866 \\
6.71 & 70.236 & 105 & 1.433 & 15 & 30 & 0.68 & 24.86 & 0.0204 & 0.0576 & 0.6034 & 0.287 & 0.1948 \\
6.71 & 70.236 & 105 & 1.433 & 15 & 45 & 0.68 & 24.86 & 0.0204 & 0.0576 & 0.6034 & 0.314 & 0.2133 \\
6.71 & 70.236 & 105 & 1.433 & 15 & 60 & 0.68 & 24.86 & 0.0204 & 0.0576 & 0.6034 & 0.344 & 0.2342 \\
6.71 & 70.236 & 105 & 1.433 & 15 & 75 & 0.68 & 24.86 & 0.0204 & 0.0576 & 0.6034 & 0.404 & 0.2750 \\
6.71 & 70.236 & 105 & 1.433 & 15 & 90 & 0.68 & 24.86 & 0.0204 & 0.0576 & 0.6034 & 0.485 & 0.3298 \\
6.71 & 70.236 & 105 & 1.433 & 15 & 105 & 0.68 & 24.86 & 0.0204 & 0.0576 & 0.6034 & 0.588 & 0.3997 \\
6.71 & 70.236 & 105 & 1.433 & 15 & 120 & 0.68 & 24.86 & 0.0204 & 0.0576 & 0.6034 & 0.722 & 0.4909 \\
6.71 & 70.236 & 105 & 1.433 & 15 & 135 & 0.68 & 24.86 & 0.0204 & 0.0576 & 0.6034 & 0.857 & 0.5825 \\
6.71 & 70.236 & 105 & 1.433 & 15 & 150 & 0.68 & 24.86 & 0.0204 & 0.0576 & 0.6034 & 0.976 & 0.6636 \\
6.71 & 70.236 & 105 & 1.433 & 15 & 165 & 0.68 & 24.86 & 0.0204 & 0.0576 & 0.6034 & 1.012 & 0.6880 \\
6.71 & 70.236 & 106 & 1.433 & 15 & 180 & 0.68 & 24.86 & 0.0204 & 0.0576 & 0.6034 & 1.000 & 0.6798 \\
\hline
\end{tabular}

\section{Kesimpulan}

a) Dari hasil analisa tinggi gelombang dengan menggunakan software surface water modeling system (sms), tinggi gelombang yang sampai dibibir pantai rata - rata sebesar $0.86 \mathrm{~m}$ sedangkan kombinasi groin dan detached breakwater mereduksi tinggi gelombang yang sampai ke pantai hingga 0.26 $\mathrm{m}$. Hasil tersebut menunjukkan efektifitas bangunan pengaman pantai sebesar $30.23 \%$.

b) Hasil perhitungan deformasi gelombang menggunakan pemodelan numerik menunjukkan hasil yang mendekati dengan perhitungan secara analitik sehingga pemodelan dapat digunakan untuk memperoleh salah satu parameter efektifitas yaitu reduksi tinggi gelombang,

\section{Referensi}

CERC, 1984. Shore Protection Manual (SPM) Volume I. US Army Coastal Engineering Research Center. Washington DC.

CERC, 1984. Shore Protection Manual (SPM) Volume II. US Army Coastal Engineering Research Center. Washington DC.
CERC, 2002. Coastal Engineering Manual (CEM). U.S. Army Corps of Engineers (USACE) manuals. Washington DC.

Hurdle, D.P., Stive, R.J.H., 1989. Revision of SPM 1984 wave hindcast model to avoid inconsistencies in engineering applications. Coastal Eng., 12: 339-351.

Sorensen, Robert M., 1978. Basic Coastal Engineering. Canada.

Warnken, J., Mosadegh, R., 2018. Challenges of implementing integrated coastal zone management into local planning policies, a case study of Queensland, Australia. 